\title{
Determining Radio Frequency Heating Uniformity of Mixed Beans for Disinfestation Treatments
}

\author{
S. Jiao, J. Tang, J. A. Johnson, G. Tiwari, S. Wang
}

\begin{abstract}
Chickpeas and lentils are two important legumes grown in the U.S. that need phytosanitary treatments before export to several countries, but it is difficult to artificially infest them with live cowpea weevil for radio frequency (RF) treatment validation. To evaluate the more readily infested black-eyed peas and mung beans as surrogates for chickpeas and lentils, the thermal and dielectric properties of black-eyed peas and mung beans at selected moisture contents were measured and compared with those of chickpeas and lentils. Temperature differences between black-eyed pea and chickpea or between mung bean and lentil were determined in a pilot-scale $27 \mathrm{MHz} R \mathrm{~F}$ unit. The results showed that the dielectric constant and loss factor of black-eyed pea and mung bean increased with increasing moisture content and temperature, which was in good agreement with the trends observed in chickpea and lentil. After 6 min of RF heating, temperatures in black-eyed pea (moisture content of $8.8 \%$ w.b.) were $6^{\circ} \mathrm{C}$ higher than those in chickpea (moisture content of $7.0 \%$ w.b.), while after 10 min of RF heating mung bean temperatures (moisture content of $10.2 \%$ w.b.) were $4^{\circ} \mathrm{C}$ higher than lentil temperatures (moisture content of $7.1 \%$ w.b.) under the same treatment conditions. By reducing the moisture contents in black-eyed pea and mung bean to $2.6 \%$ and $3.7 \%$ w.b., respectively, their final temperatures were about $3.5^{\circ} \mathrm{C}$ and $3.7^{\circ} \mathrm{C}$ lower than those of chickpea and lentil. This would result in conservative insect mortality results when using black-eyed pea and mung bean as surrogate hosts for validation of pest control treatments in chickpea and lentil.
\end{abstract}

Keywords. Dielectric properties, Heating rate, Infestation, Legume, Radio frequency.

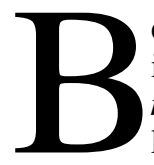
ecause of the occurrence of natural field infestations of cowpea weevil (Callosobruchus maculatus) in chickpea (Cicer arietinum) and lentil (Lens culinaris), the U.S. legume industry is required to meet postharvest phytosanitary regulations before export to India, Korea, Spain, and Latin American countries (USADPLC, 2007). The most common method for postharvest insect control in legumes is fumigation with methyl bromide (MeBr) (Carpenter et al., 2000). However, because $\mathrm{MeBr}$ reduces the stratospheric ozone layer, the amount of $\mathrm{MeBr}$ produced and imported in the U.S. is being incrementally reduced and is not available for most postharvest applications (Browner, 1999; UNEP, 2006). Radio frequency (RF) heating has potential as an alternative method for insect control in legumes.

Industrial RF equipment is commercially available today and is used for final drying of numerous products, including

Submitted for review in April 2011 as manuscript number FPE 9170; approved for publication by the Food \& Process Engineering Institute Division of ASABE in September 2011.

The authors are Shunshan Jiao, Graduate Student, and Juming Tang, ASABE Member, Professor, Department of Biological Systems Engineering, Washington State University, Pullman, Washington; Judy A. Johnson, Research Entomologist, USDA-ARS San Joaquin Valley Agricultural Sciences Center, Parlier, California; Gopal Tiwari, Postdoctoral Research Associate, Department of Biological and Agricultural Engineering, University of California, Davis, California; and Shaojin Wang, ASABE Member, Assistant Research Professor, Department of Biological Systems Engineering, Washington State University, Pullman, Washington. Corresponding author: Shaojin Wang, Northwest A\&F University, College of Mechanical and Electronic Engineering, Yangling, Shaanxi 712100, China; phone: +86-2987092391; fax: +86-29-87091737; e-mail: shaojin_wang@wsu.edu. crackers, yarn, and paper (Piyasena et al., 2003). RF heating involves direct propagation of electromagnetic energy through bulk materials, initiating volumetric heating (Tang et al., 2000). In most RF systems, the product forms a "dielectric" mass between pairs of electrodes, which are alternatively charged positively and negatively with RF energy at frequencies between 10 and $100 \mathrm{MHz}$. Rotation of polar molecules and movement of charged ions are the two main contributors of RF heat generation in the product (Barber, 1983). RF energy can rapidly raise the temperature throughout the treated product in an industrial system. RF heating also has the advantage of deeper penetration over microwave energy in bulk materials, providing better heating uniformity and is thus more suitable for thermal treatments of those materials (Wang et al., 2003b).

Many studies have explored the use of RF heating for control of insects in agricultural commodities (Andreuccetti et al., 1994; Marra et al., 2009; Nelson, 1996; Nelson and Payne, 1982; Tang et al., 2000). Lagunas-Solar et al. (2007) reported RF control of insects in rough rice with acceptable quality. Wang et al. (2001, 2002) and Mitcham et al. (2004) developed pilot-scale RF treatments for control of codling moth and navel orangeworm in in-shell walnuts. Wang et al. (2007a, 2007b) demonstrated acceptable product quality using an industrial-scale conveyorized RF system for in-shell walnuts, validating the efficacy of the treatment using fifthinstar navel orangeworms. Recently, Wang et al. (2010) studied postharvest disinfestation treatments for chickpeas and lentils using RF energy. RF heating uniformity was improved by adding forced hot air and movement on a conveyor belt at $0.56 \mathrm{~m} \mathrm{~min}^{-1}$ in a $6 \mathrm{~kW}, 27 \mathrm{MHz}$ pilot-scale system. To validate the RF treatment protocol, efficacy tests 
that treat product infested with the most tolerant stage of the target insect must be done.

Although cowpea weevil has been associated with both chickpeas and lentils (Arbogast, 1991), Ahmed et al. (1989) showed that some varieties of chickpeas were very poor hosts for cowpea weevil, and Islam et al. (2007) reported that lentils were not preferred by ovipositing females. Our preliminary observations showed that our USDA-ARS cowpea weevil isolate reared on black-eyed pea (Vigna unguiculata) produced very few eggs on available chickpea and lentil varieties. However, we found cowpea weevil oviposition and development on mung bean (Vigna radiata), a bean known to support cowpea weevil development (Arbogast, 1991), to be similar to that on black-eyed peas. Because of the poor oviposition on chickpeas and lentils, we selected black-eyed peas and mung beans, similar in size to chickpeas and lentils, respectively, as surrogate hosts in validation tests. Infested surrogate hosts were placed within chickpeas and lentils during RF treatments. To obtain conservative validation results, chickpeas and lentils used for quality evaluation should reach slightly higher temperatures than infested black-eyed peas and mung beans.

In RF treatments, heating rates in mixed beans are proportional to the dielectric loss factor of individual beans in bulk (Nelson, 1996; Wang et al., 2003a). Because the loss factor of legumes increases with increasing moisture content (Guo et al., 2008, 2010; Jiao et al., 2011), it is possible to adjust the RF heating rates in samples by controlling the sample moisture contents under the given electric field intensity in validation studies.

The objectives of this study were: (1) to study selected physical and dielectric properties of black-eyed peas, mung beans, chickpeas, and lentils relevant to RF heating for insect control; (2) to compare the temperature-time history and final temperatures of legumes when subjected to $27 \mathrm{MHz} \mathrm{RF}$ heating; and (3) to determine the moisture contents needed to achieve heating rates in black-eyed pea and mung bean that are slightly lower than those in chickpea and lentil.

\section{Materials AND Methods}

\section{Bulk Density and True Density Measurement}

Chickpea and lentil were purchased from George Brocke \& Sons, Inc. (Kendrick, Ida.), black-eyed peas from Pacific Grain \& Foods (Fresno, Cal.), and mung beans from Living Whole Foods, Inc. (Springville, Utah). The initial moisture contents of chickpea, lentil, black-eyed pea, and mung bean were $7.0 \%, 7.1 \%, 8.8 \%$, and $10.2 \%$ on wet basis (w.b.), respectively.

The bulk densities of four types of legumes at room temperature were measured by a basic volume method using a $25.5 \times 15 \times 10 \mathrm{~cm}$ container (fig. 1 ). For each legume, the container was filled with product and then weighed. Mean and standard deviation values of bulk density were estimated over three replicates.

The true density of black-eyed pea and mung bean was measured using the liquid displacement method at four moisture content levels (black-eye pea: 8.8\%, 12.8\%, 16.8\% and $20.8 \%$ w.b.; mung bean: $10.2 \%, 14.2 \%, 18.2 \%$ and $22.2 \%$ w.b.). To prepare the samples at different moisture levels, a predetermined amount of water calculated to provide a difference in moisture content of about $4 \%$ between
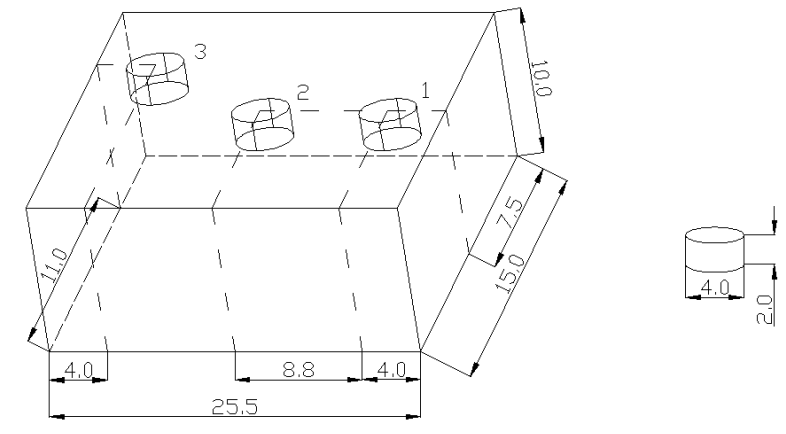

Figure 1. Experimental plastic treatment container (also used for bulk density measurement) with location of three cups $(1,2$, and 3 ) for sample temperature measurements (all dimensions are in $\mathbf{c m}$ ).

levels was added to weighed legume samples. The moistened samples were then shaken to distribute the water and finally stored at $4{ }^{\circ} \mathrm{C}$ for four days in a refrigerator to ensure that the samples achieved a uniform moisture distribution (Guo et al., 2008). The moistened samples were taken out of the refrigerator and allowed to equilibrate at room temperature for one more day before measurement (Guo et al., 2008). To avoid water absorption in legumes during density measurement, toluene $\left(\mathrm{C}_{6} \mathrm{H}_{5} \mathrm{CH}_{3}\right)$ was used as a displacement liquid because it shows little tendency to permeate through the sample and has stable specific gravity and viscosity (Guo et al., 2010). The true density was determined by dividing the weight of randomly selected $10 \mathrm{~g}$ samples by the volume occupied by the samples as measured with toluene in $50 \mathrm{~mL}$ pycnometers. The measurements were replicated three times, and the mean true densities were calculated for each legume.

\section{Specific Heat Measurement}

The specific heat of black-eyed pea, chickpea, mung bean, and lentil was measured with a differential scanning calorimeter (DSC, Q2000, TA Instruments, New Castle, Del.). The legumes were cut into small pieces, and samples of about $10 \mathrm{mg}$ each were sealed in small aluminum pans $(30 \mu \mathrm{L})$. The samples were heated in the DSC at a rate of

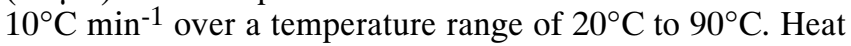
flux data from the samples were taken over the temperature range at $0.03^{\circ} \mathrm{C}$ increments and used to calculate the specific heat based on the measurement of the reference samples. The measurements for each legume were replicated twice. Since the moisture content of samples was low ( $<10.2 \%$ w.b.) and the sample was sealed, effects of evaporation on the specific heat could be ignored during measurement (Tang et al., 1991).

\section{Dielectric Properties Measurement}

Permittivity describes the dielectric properties that influence RF heating of target products, and the relative complex permittivity $(\varepsilon)$ can be expressed through the following equation:

$$
\varepsilon=\varepsilon^{\prime}-j \varepsilon^{\prime}
$$

where the real part $\left(\varepsilon^{\prime}\right)$ is the dielectric constant, the imaginary part $\left(\varepsilon^{\prime \prime}\right)$ is the dielectric loss factor (also known as dissipation factor), and $j=\sqrt{-1}$. The dielectric constant represents the material's ability to store electrical energy, while the dielectric loss factor reflects its ability to dissipate 
electrical energy as heat (Mudgett, 1994). Dielectric properties directly influence the RF power in the electromagnetic field, which can be expressed as (Nelson, 1996):

$$
P=5.56 \cdot 10^{-11} f E^{2} \varepsilon^{\prime \prime}
$$

where $P$ is the absorbed RF power density $\left(\mathrm{W} \mathrm{m}^{-3}\right)$ in a legume sample, $f$ is frequency $(\mathrm{Hz})$, and $E$ is electric field intensity $\left(\mathrm{V} \mathrm{m}^{-1}\right)$.

Data on the dielectric properties of lentil and chickpea are available in the literature (Guo et al., 2008, 2010). The dielectric properties of mung bean and black-eyed pea samples were measured in this study using an open-ended coaxial-line probe connected to an impedance analyzer (HP4291B, Hewlett Packard Corp., Santa Clara, Cal.). After following the standard calibration procedure, the dielectric properties were determined over frequencies of 10 to $1800 \mathrm{MHz}$, temperatures of $20^{\circ} \mathrm{C}$ to $90^{\circ} \mathrm{C}$, and four moisture levels. Detailed information about the dielectric property measurement system and procedure can be found elsewhere (Guo et al., 2008; Jiao et al., 2011; Wang et al., 2003b). The measurements were replicated two times.

Since the irregularly shaped legume samples do not make good contact with the flat probe surface for accurate measurements, compressed pellets made of homogeneous legume flour were used. The flour was prepared from legume seeds by grinding in a coffee grinder, and the pellets were compressed in a mold using a hydraulic press (Fred S. Carver, Inc. Summit, N.J.). Because the dielectric properties of particulate materials are affected by sample density (Berbert et al., 2002), the true density of each legume was used as the criterion for compressing the flour samples, as described by Guo et al. (2008).

The moisture contents of legume flours were determined by the vacuum oven drying method. About 2 to $3 \mathrm{~g}$ flour samples were placed in aluminum dishes and then dried in a vacuum oven (ADP-31, Yamato Scientific America, Inc., Santa Clara, Cal.) at $130^{\circ} \mathrm{C}$ and 75 to $85 \mathrm{kPa}$ for $1 \mathrm{~h}$ (AOAC, 2002). The samples were placed in desiccators with $\mathrm{CaSO}_{4}$ to bring them to room temperature before weighing. There were three replicates for each legume flour sample. The water activity $\left(a_{w}\right)$ of each sample was measured in an Aqualab water activity meter (Series 3, Decagon Devices, Inc., Pullman, Wash.) with an accuracy of $\pm 0.003 a_{w}$, and measurements were conducted in triplicate at room temperature $\left(23^{\circ} \mathrm{C}\right)$.

\section{RF Heating Systems}

A $6 \mathrm{~kW}, 27 \mathrm{MHz}$ pilot-scale RF system (COMBI 6-S, Strayfield International, Wokingham, U.K.) was used to determine the heating rates and uniformity in the mixed beans. A detailed description of the RF system can be found in Wang et al. (2010). In the current study, legume samples in a plastic container $(25.5 \times 15 \times 10 \mathrm{~cm})($ fig. 1$)$ were placed on the center of the bottom plate electrode without hot air or no movement of the conveyor belt. The gap between two electrodes was fixed at $13.3 \mathrm{~cm}$ to achieve an appropriate heating rate based on a previous study (Wang et al., 2010).

In general, when the dimension of the top electrode is less than $30 \%$ of the RF wavelength, its voltage can be assumed to be uniformly distributed (Barber, 1983). In the current RF unit, because the top plate electrode dimensions $(0.7 \times$
$0.5 \mathrm{~m}^{2}$ ) were far less than $30 \%$ of an RF wavelength at the frequency of $27.12 \mathrm{MHz}(11 \mathrm{~m})$, we assumed that the voltage distribution on the top electrode was uniform. We also assumed that the top electrode voltage remains constant during the RF treatment since the voltage in industrial-scale RF systems varies very little (less than 7\%) for the different load positions (Metaxas, 1996).

With the above assumptions and when neglecting the heat loss from beans to the surroundings, the heating rates in the two mixed beans ( 1 and 2 ) due to the same RF heating were governed by the following energy balance equations:

$$
\left\{\begin{array}{l}
\rho_{1} C_{p 1} \frac{d T_{1}}{d t}=5.56 \cdot 10^{-11} f E_{1}^{2} \varepsilon_{1} \\
\rho_{2} C_{p 2} \frac{d T_{2}}{d t}=5.56 \cdot 10^{-11} f E_{2}{ }^{2} \varepsilon_{2}
\end{array}\right.
$$

where $C_{p}$ is the specific heat $\left(\mathrm{J} \mathrm{kg}^{-1}{ }^{\circ} \mathrm{C}^{-1}\right), \rho$ is the density $\left(\mathrm{kg} \mathrm{m}^{-3}\right), T$ is the sample temperature $\left({ }^{\circ} \mathrm{C}\right)$ and $t$ is the RF heating time (s).

The heating time $(t)$ and frequency $(f)$ are identical under the same RF treatment, but the electric field intensity in different materials is theoretically different. Since the amount of black-eyed pea and mung bean in the current experiments was very small $(\sim 2 \%)$ compared to that of chickpea and lentil, the difference in electric field intensity between two different legumes was less than $10 \%$ according to our preliminary computer simulation results. Thus, we ignored the influence caused by the slight difference in the electric field intensity among the two different legumes in the same RF system. This was also assumed for insects and the host materials in microwave and RF heating (Ben-Lalli et al., 2011; Wang et al., 2003a). The heating rate ratio for any two legumes can be calculated from the loss factor, density, and specific heat to provide a temperature change ratio:

$$
\frac{\Delta T_{1}}{\Delta T_{2}}=\frac{\varepsilon^{\prime}{ }_{1} / \rho_{1} C_{p 1}}{\varepsilon{ }_{2} / \rho_{2} C_{p 2}}
$$

If $\Delta T_{1} / \Delta T_{2}>1$, then the heating rate of sample 1 is greater than that of sample 2 during the same RF treatment, and the temperature rise in sample 1 is higher than that in sample 2 at any time during the treatment. The temperature change ratios between black-eyed pea and chickpea and between mung bean and lentil were calculated from the specific heat, density, and dielectric loss factors at each of five temperatures measured for each legume.

We compared the mean heating rates calculated from equation 4 with experimentally derived values for the target legumes and their surrogates (black-eyed pea with chickpea, and mung bean with lentil) in the same RF field. Three small cylindrical plastic cups $(4 \mathrm{~cm}$ dia. $\times 2 \mathrm{~cm}$ deep) filled with legumes (16 to $19 \mathrm{~g}$ ) were buried in a larger test container $(25.5 \times 15 \times 10 \mathrm{~cm})$ also filled with legumes $(3 \mathrm{~kg})$. The cups were buried at three representative locations (fig. 1) so that the legume surface within the cup was level with that of the larger container. Comparisons were made in four different sample arrangements in the RF unit: (1) both the larger container and the cups were filled with chickpeas, (2) both the larger container and the cups were filled with lentils, (3) the larger container was filled with chickpeas and the cups were filled with black-eyed peas, and (4) the larger 
container was filled with lentils and the cups were filled with mung beans.

The container was subjected to RF heating from room temperature $\left(23^{\circ} \mathrm{C}\right)$ until the sample temperature reached about $60^{\circ} \mathrm{C}$. The temperatures of the beans were measured and recorded with a FISO optic temperature measurement system (UMI, FISO Technologies, Inc., Saint-Foy, Quebec, Canada) during RF heating. One sensor was placed in the center of the middle cup (cup 2), and another one was located near the external wall of cup 2. After RF heating, the surface temperatures of the samples were immediately measured with a digital infrared camera (Thermal CAMTM SC-3000, FLIR Systems, Inc., North Billerica, Mass.), which had an accuracy of $\pm 2{ }^{\circ} \mathrm{C}$.

To provide a more conservative evaluation of insect mortality and product quality, the surrogate products (blackeyed peas and mung beans) should heat less than chickpeas and lentils. To reduce the heating rate of the surrogate products during RF heating, the moisture contents of blackeyed pea and mung bean were reduced by hot air drying to $2.6 \%$ and $3.7 \%$, respectively. The dried black-eyed peas and mung bean samples were heated in RF treatments along with chickpeas and lentils to determine the final temperature for analyses.

\section{Results AND ANALYSES}

\section{Bulk Density, True Density, and Specific Heat}

The bulk density and initial moisture contents of the four tested legumes are shown in table 1. Mung bean had the highest bulk density, followed by chickpea, lentil, and blackeyed pea. The true densities of black-eyed pea and mung bean as a function of moisture content at room temperature are listed in table 2. The true densities of both black-eyed pea and mung bean decreased with increasing moisture content. This trend was also observed for chickpea and lentil (Guo et al., 2010). Chickpea had much higher true density than blackeyed pea regardless of the moisture levels, but mung bean had slightly higher values than lentil only at low moisture content levels (Guo et al., 2010).

The specific heat of the four tested legumes as a function of temperature is summarized in figure 2. For all four legumes, the specific heat increased with increasing

Table 1. Bulk density of four types of legumes at their original moisture content and ambient temperature $\left(23^{\circ} \mathrm{C}\right)$.

\begin{tabular}{ccc}
\hline Legumes & $\begin{array}{c}\text { Moisture Content } \\
(\% \text { w.b. })\end{array}$ & $\begin{array}{c}\text { Bulk Density } \\
\left(\mathrm{kg} \mathrm{m}^{-3}\right)\end{array}$ \\
\hline Black-eyed pea & 8.8 & $690 \pm 3$ \\
Chickpea & 7.0 & $826 \pm 6$ \\
Mung bean & 10.2 & $920 \pm 6$ \\
Lentil & 7.1 & $791 \pm 4$ \\
\hline
\end{tabular}

Table 2. True densities of black-eyed pea and mung bean at four moisture content (MC) levels and ambient temperature $\left(23^{\circ} \mathrm{C}\right)$.

\begin{tabular}{ccccc}
\hline \multicolumn{2}{c}{ Black-Eyed Pea } & & \multicolumn{2}{c}{ Mung Bean } \\
\cline { 1 - 2 } \cline { 5 - 5 } $\begin{array}{c}\text { MC } \\
(\% \text { w.b. })\end{array}$ & $\begin{array}{c}\text { True Density } \\
\left(\mathrm{kg} \mathrm{m}^{-3}\right)\end{array}$ & & $\begin{array}{c}\text { MC } \\
(\% \text { w.b. })\end{array}$ & $\begin{array}{c}\text { True Density } \\
\left(\mathrm{kg} \mathrm{m}^{-3}\right)\end{array}$ \\
\hline 8.8 & $1133 \pm 15$ & & 10.2 & $1455 \pm 3$ \\
12.8 & $1113 \pm 13$ & & 14.2 & $1363 \pm 12$ \\
16.8 & $1097 \pm 4$ & & 18.2 & $1305 \pm 3$ \\
20.8 & $1091 \pm 2$ & & 22.2 & $1258 \pm 13$ \\
\hline
\end{tabular}

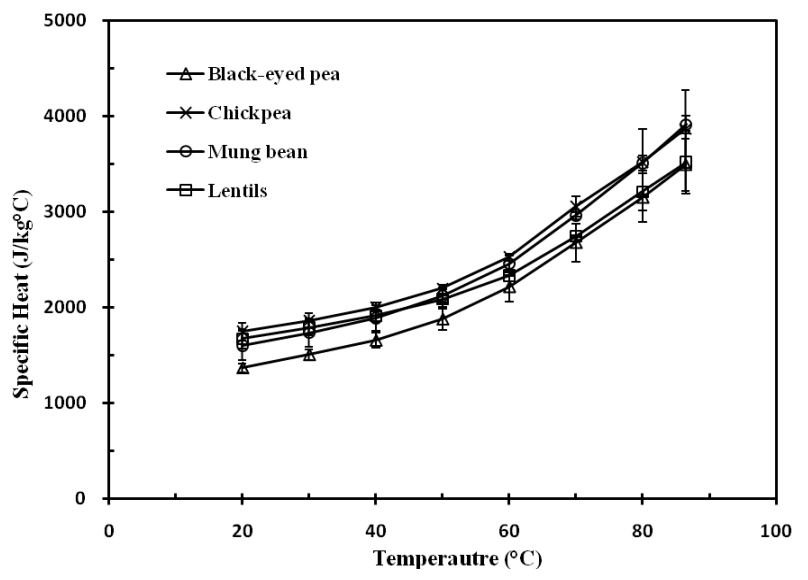

Figure 2. Specific heat of four types of legumes as a function of temperature at initial moisture contents.

temperature in the range of $20^{\circ} \mathrm{C}$ to $90^{\circ} \mathrm{C}$. This trend is similar to that found for corn and rice, as reported by ValdezFragoso et al. (2001), and for Laird lentils (Tang et al., 1991). There were relatively large differences in the specific heat between chickpea and black-eyed pea. The specific heat of mung bean and lentil was similar (less than $3 \%$ ) at or below temperatures proposed for disinfestation treatments $\left(60^{\circ} \mathrm{C}\right)$.

\section{Water Activities and Dielectric Properties}

Table 3 shows the water activity values of black-eyed pea and mung bean at four different moisture contents at ambient temperature $\left(23^{\circ} \mathrm{C}\right)$. For both black-eyed pea and mung bean, water activity increased with increasing moisture content. This relationship could be used to estimate the moisture content by measuring water activity during sample preparation for dielectric property measurements.

The dielectric constant and loss factor at $27 \mathrm{MHz}$ of blackeyed pea and chickpea as a function of moisture content and temperature are shown in figure 3 . The dielectric properties of black-eyed pea increased with temperature and moisture content (fig. 3a), which was also observed for chickpea (Guo et al., 2008) (fig. 3b). By comparison, the dielectric constant of black-eyed pea was close to that of chickpea when the temperature was below $60^{\circ} \mathrm{C}$ for all four moisture content levels, but the loss factor of black-eyed pea was lower than that of chickpea, especially at high moisture contents and temperature levels. This is probably caused by their differences in true density.

The dielectric properties of mung bean and lentil at $27 \mathrm{MHz}$ as a function of moisture content and temperature are shown in figure 4 . The same increasing dielectric properties with temperature and moisture content were found for both mung bean (fig. 4a) and lentil (Guo et al., 2010) (fig. 4b). The dielectric constant and loss factor of mung bean

\begin{tabular}{|c|c|c|c|}
\hline \multicolumn{2}{|c|}{ Black-Eyed Pea } & \multicolumn{2}{|c|}{ Mung Bean } \\
\hline $\begin{array}{c}\mathrm{MC} \\
(\% \text { w.b. })\end{array}$ & $\begin{array}{c}\text { Water } \\
\text { Activity }\end{array}$ & $\begin{array}{c}\text { MC } \\
\text { (\% w.b.) }\end{array}$ & $\begin{array}{c}\text { Water } \\
\text { Activity }\end{array}$ \\
\hline 8.8 & $0.461 \pm 0.001$ & 10.2 & $0.496 \pm 0.005$ \\
\hline 12.7 & $0.660 \pm 0.001$ & 14.4 & $0.705 \pm 0.001$ \\
\hline 16.8 & $0.777 \pm 0.001$ & 18.2 & $0.814 \pm 0.004$ \\
\hline 20.9 & $0.850 \pm 0.002$ & 22.3 & $0.892 \pm 0.003$ \\
\hline
\end{tabular}



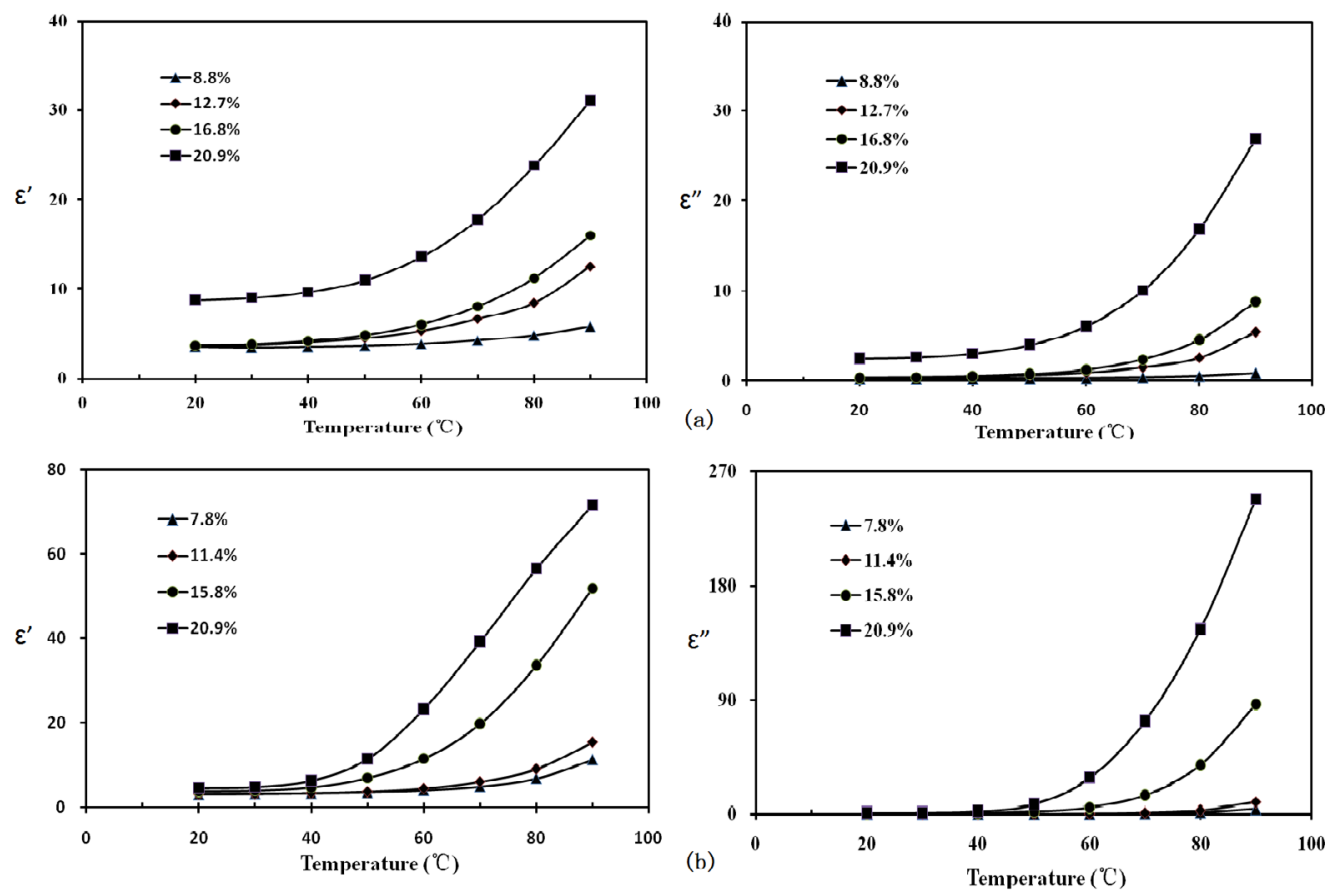

Figure 3. Dielectric properties of (a) black-eyed peas and (b) chickpeas at $27 \mathrm{MHz}$ as a function of moisture contents and temperatures. Data for chickpeas are from Guo et al. (2008).
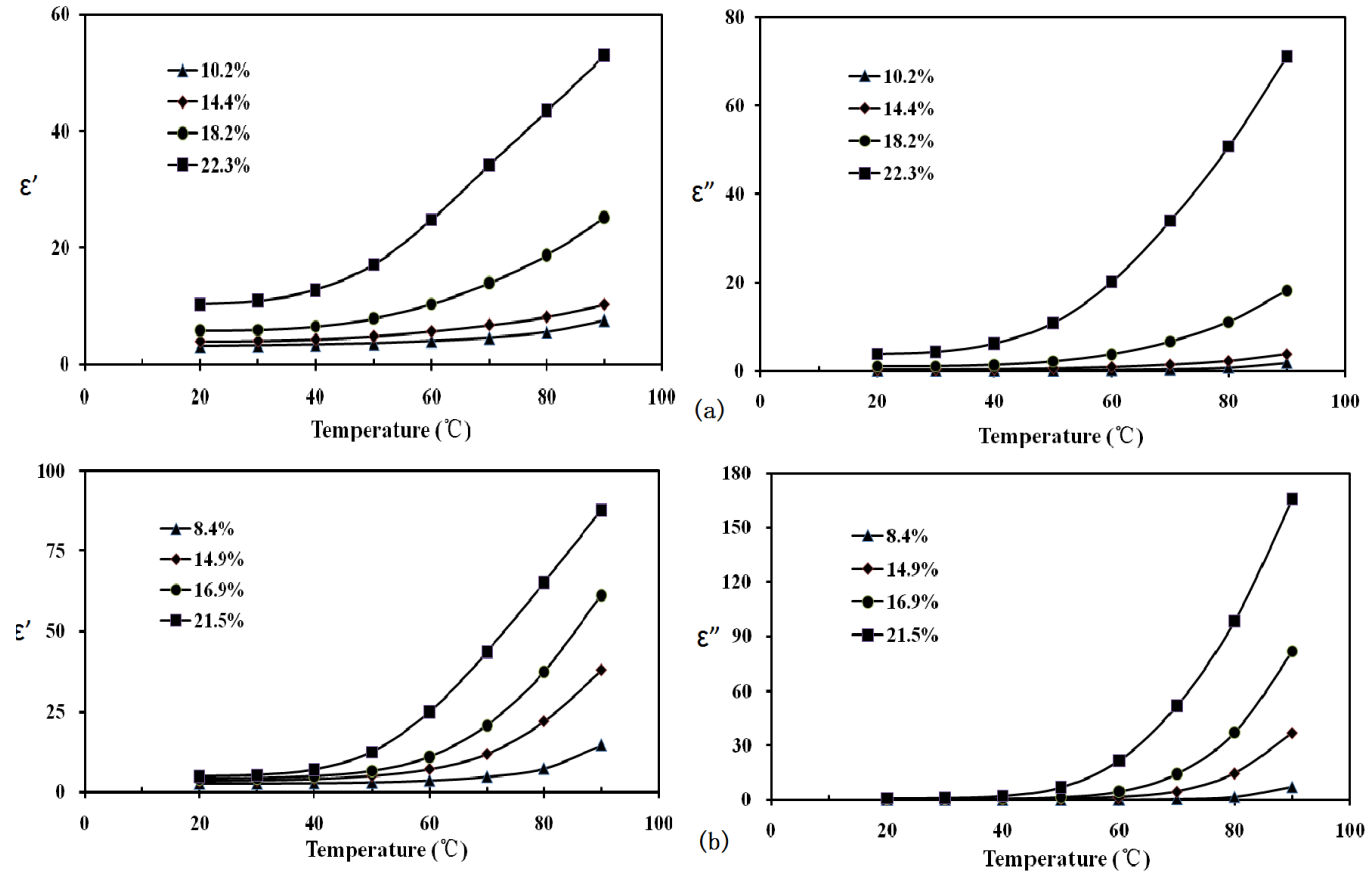

Figure 4. Dielectric properties of (a) mung beans and (b) lentils at $27 \mathrm{MHz}$ as a function of moisture contents and temperatures. Data for lentils are from Guo et al. (2010).

were both similar to those of lentil when the temperature was below $60^{\circ} \mathrm{C}$ at each moisture content level.

\section{RF HEATING RATES AND UNIFORMiTy}

Figures $5 \mathrm{a}$ and $5 \mathrm{~b}$ show the temperature-time histories during RF heating of chickpea when cup 2 was filled with chickpea and black-eyed pea, respectively. The temperaturetime history in the center of cup 2 when filled with chickpea was almost the same as that outside the cup (fig. 5a), suggesting that the temperature difference caused by the three small cups was negligible. The final temperature in the center of cup 2 was slightly higher $\left(0.8^{\circ} \mathrm{C}\right)$ than that outside. We observed in the thermal image a $1.0^{\circ} \mathrm{C}$ difference between the bean surface at the center of the cup and the surrounding bean surface (fig. 6a). However, when the cups were filled with black-eyed pea, there was a relatively large temperature difference between the center of cup 2 and the outside of the cup (fig. 5b). The final temperature in black- 

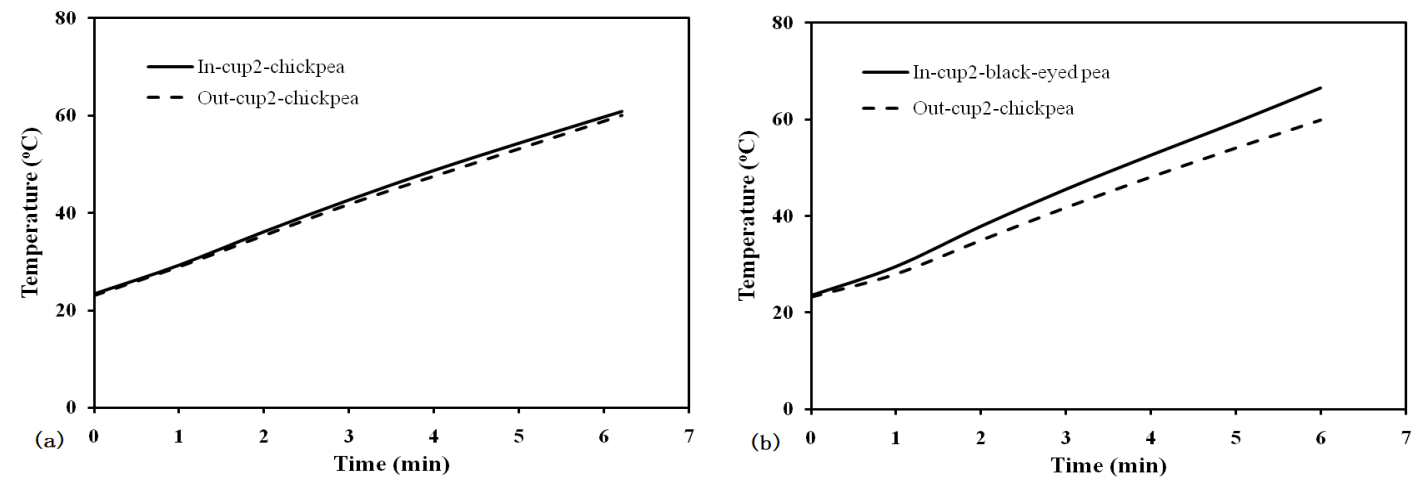

Figure 5. Temperature-time histories during RF heating under an electrode gap of $13.3 \mathrm{~cm}$ for chickpeas inside and outside cup 2 when filled with (a) chickpea and (b) black-eyed pea at initial moisture contents.
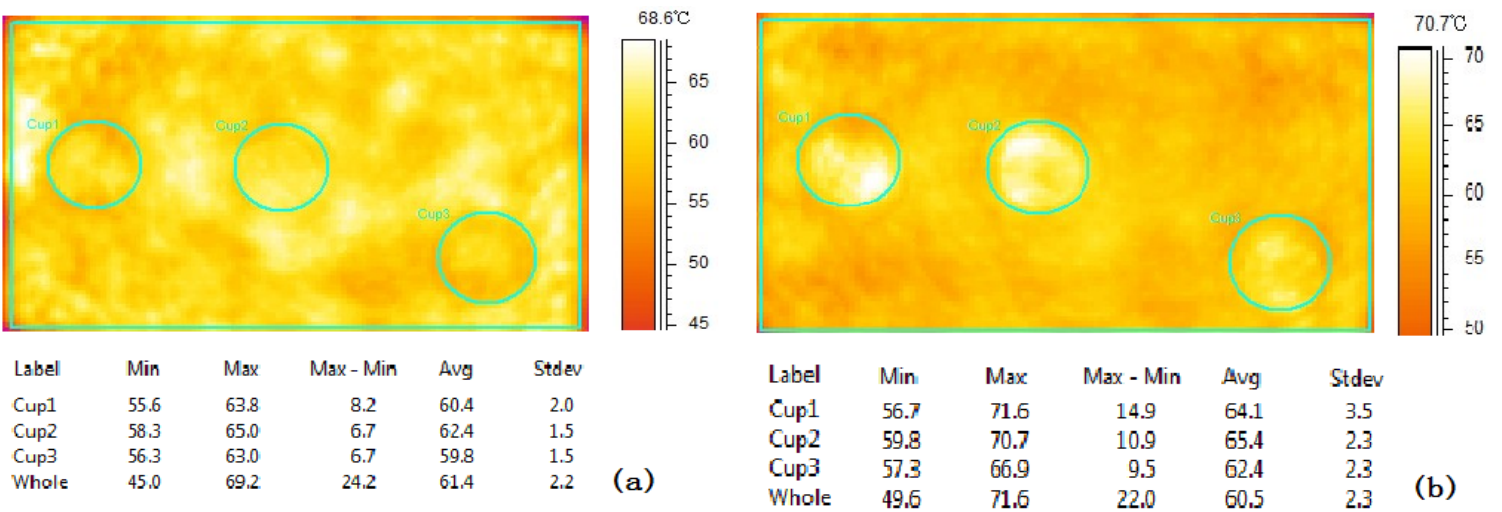

Figure 6. Thermal images after $6 \mathrm{~min}$ RF heating under an electrode gap of $13.3 \mathrm{~cm}$ for chickpeas when cups were filled with (a) chickpea and (b) blackeyed pea at initial moisture contents.

\begin{tabular}{|c|c|c|}
\hline $\begin{array}{c}\text { Temperature } \\
\left({ }^{\circ} \mathrm{C}\right)\end{array}$ & $\begin{array}{c}\Delta T_{1} / \Delta T_{2} \\
\text { (Black-Eyed Pea/Chickpea) }\end{array}$ & $\begin{array}{c}\Delta T_{1} / \Delta T_{2} \\
\text { (Mung Bean/Lentil) }\end{array}$ \\
\hline 20 & 2.04 & 1.21 \\
\hline 30 & 1.47 & 1.17 \\
\hline 40 & 2.47 & 1.23 \\
\hline 50 & 2.15 & 1.14 \\
\hline 60 & 1.37 & 0.86 \\
\hline Mean & 1.90 & 1.12 \\
\hline
\end{tabular}

eyed pea was higher than that of chickpea under the same RF processing conditions, and the difference was about $6.5^{\circ} \mathrm{C}$, which was in good agreement with the mean temperature difference $\left(4.9^{\circ} \mathrm{C}\right)$ found in thermal imaging (fig. $\left.6 \mathrm{~b}\right)$. The different heating rates between black-eyed pea and chickpea were probably caused by the different ratio of the dielectric loss factor to the density and specific heat, as indicated in equation 4. The calculated ratio of heating rate between black-eyed pea and chickpea is shown in table 4 and was $>1$ for all temperatures from $20^{\circ} \mathrm{C}$ to $60^{\circ} \mathrm{C}$. This suggests that the heating rate of black-eyed pea was larger than that of chickpea, which was also observed in the experimental results. To obtain conservative insect mortality results for black-eyed pea and thereby avoid reducing chickpea quality, the heating rate in black-eyed pea could be reduced by reducing the initial moisture content based on the corresponding loss factor reduction shown in figure 3 .
Figure 7 presents the temperature-time histories during RF treatments for lentil and mung bean. When both the large container and the cups were filled with lentil, the temperature-time history in the center of cup 2 was close to that outside the cup (fig. 7a). The final temperature difference between the inside and outside of the cup 2 was about $1.2^{\circ} \mathrm{C}$ and was confirmed by the mean temperature difference $\left(0.9^{\circ} \mathrm{C}\right)$ between the three cups and the whole area of the container using thermal imaging (fig. 8a). However, when the cups were filled with mung bean, the heating rate in the center of cup 2 was higher than that outside the cup under the same RF processing conditions (fig. 7b). The final temperature in mung bean was about $4.4^{\circ} \mathrm{C}$ higher than that in lentil after RF heating for $10 \mathrm{~min}$. This was in good agreement with that found in thermal imaging (fig. 8b), indicating that the average temperatures of three cups and the whole sample surface were $59.2^{\circ} \mathrm{C}$ and $54.5^{\circ} \mathrm{C}$, respectively. This temperature difference could also be explained by the ratio of the dielectric loss factor to the density and specific heat, as indicated in equation 4 . The detailed ratios of heating rate between mung bean and lentil at different temperatures are also shown in table 4 . Even through the ratio was less than 1 when the temperature was $60^{\circ} \mathrm{C}$, the mean ratio over the five temperatures were larger than 1 . This indicated that the heating rate of mung bean in the RF unit was larger than that of lentil. In addition, the mean ratio between black-eyed pea and chickpea was larger than that between mung bean and lentil (table 4), which was in good agreement with the experimental results. 

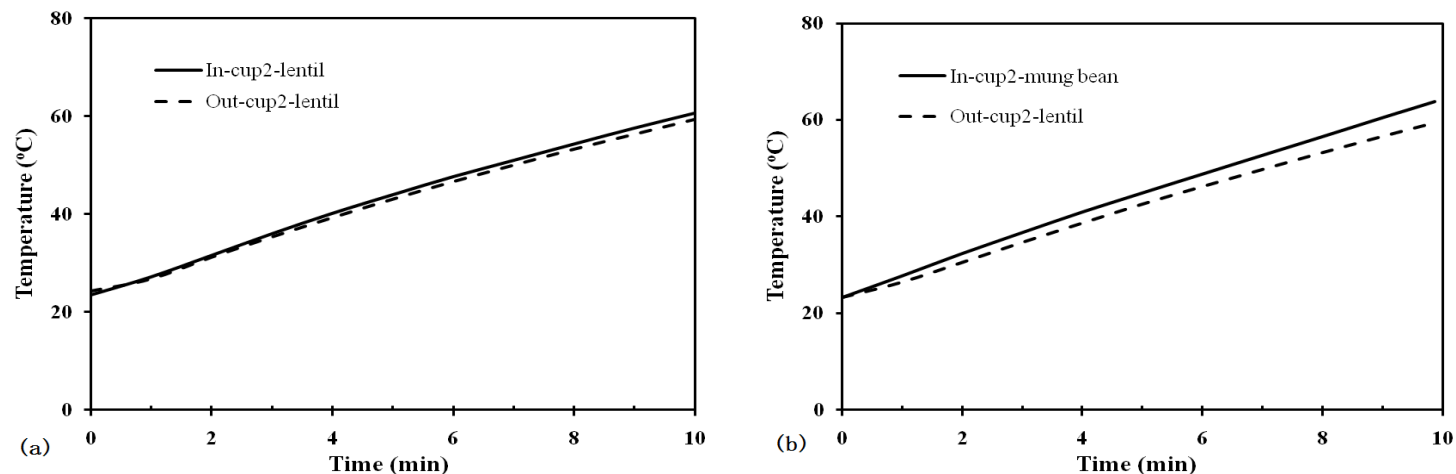

Figure 7. Temperature-time histories during RF heating under an electrode gap of $13.3 \mathrm{~cm}$ for lentils inside and outside cup 2 when filled with (b) lentil and (b) mung bean at initial moisture contents.
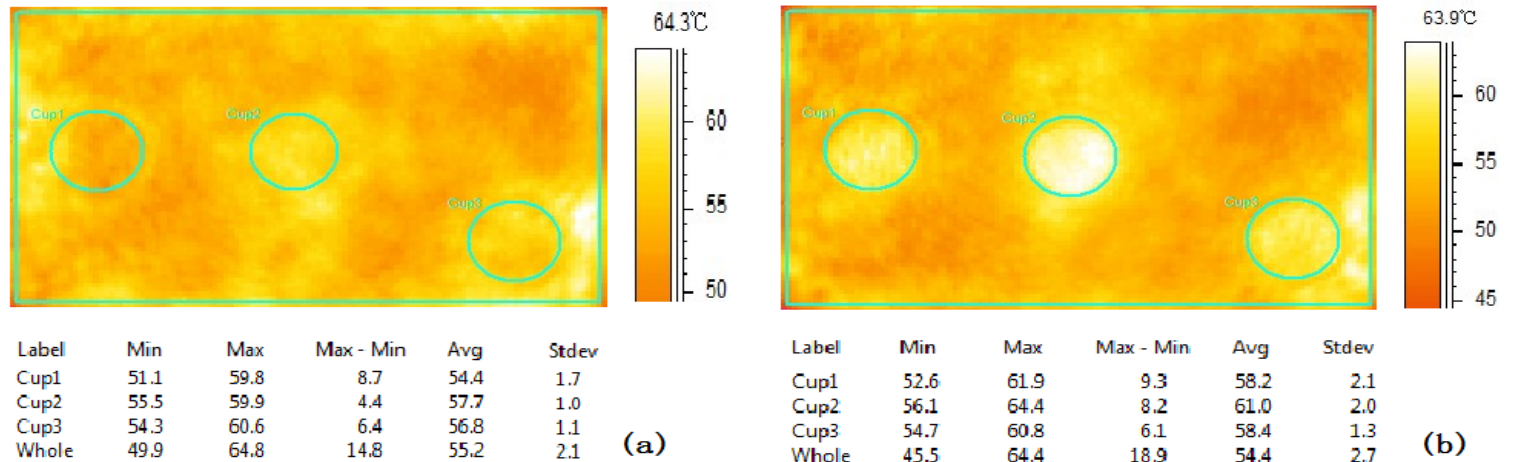

(b)

Figure 8. Thermal images after $10 \mathrm{~min}$ RF heating under the electrode gap of $13.3 \mathrm{~cm}$ for lentils when cups were filled with (a) lentil and (b) mung bean at initial moisture contents.

Since the experimental results showed that the heating rate of the proposed surrogates black-eyed pea ( $8.8 \%$ w.b.) and mung bean $(10.2 \%$ w.b.) was higher than the target products chickpea (7.0\% w.b.) and lentil $(7.1 \%$ w.b.), it was necessary to reduce the RF power absorption of the surrogates by reducing their moisture content. Figure 9 shows the temperature-time histories of black-eyed pea and mung bean with reduced moisture contents $(2.6 \%$ and $3.7 \%$ w.b., respectively) in cup 2 as compared to that outside the cup. The final temperature in black-eyed pea was about $3.5^{\circ} \mathrm{C}$ lower than that in chickpea under the same treatment conditions when the temperature of the black-eyed pea samples was raised to $60^{\circ} \mathrm{C}$ (fig. 9a), but thermal imaging (fig. 10a) resulted in a lower average temperature difference $\left(2.1^{\circ} \mathrm{C}\right)$ between the surface of the black-eyed peas and the surface of the surrounding chickpeas. The final temperature in mung bean was about $3.7^{\circ} \mathrm{C}$ lower than that in lentil (fig. 9b) while the average difference between surface temperatures was $2.0^{\circ} \mathrm{C}$ (fig. 10b). These results show that moisture content can be used to adjust the heating rates of legumes during RF treatments.
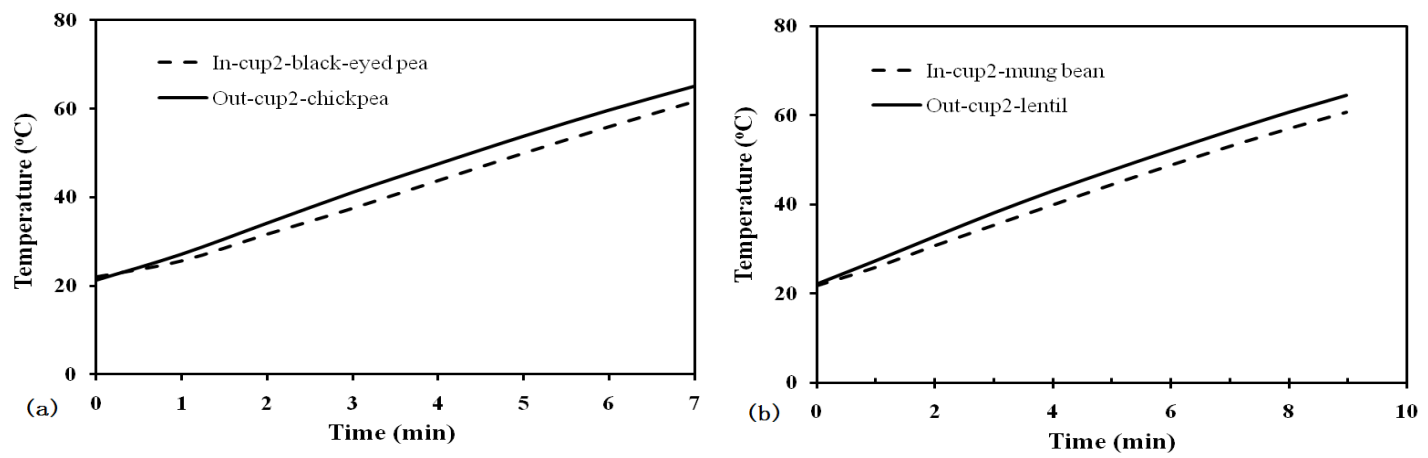

Figure 9. Temperature-time histories during RF heating under the electrode gap of $13.3 \mathrm{~cm}$ for the target legumes inside and outside cup 2 when filled with (a) chickpea in the container and black-eyed pea at the reduced moisture content of $2.6 \%$ w.b. in the cups and (a) lentil in the container and mung bean at the reduced moisture content of $3.7 \%$ w.b. in the three cups. 

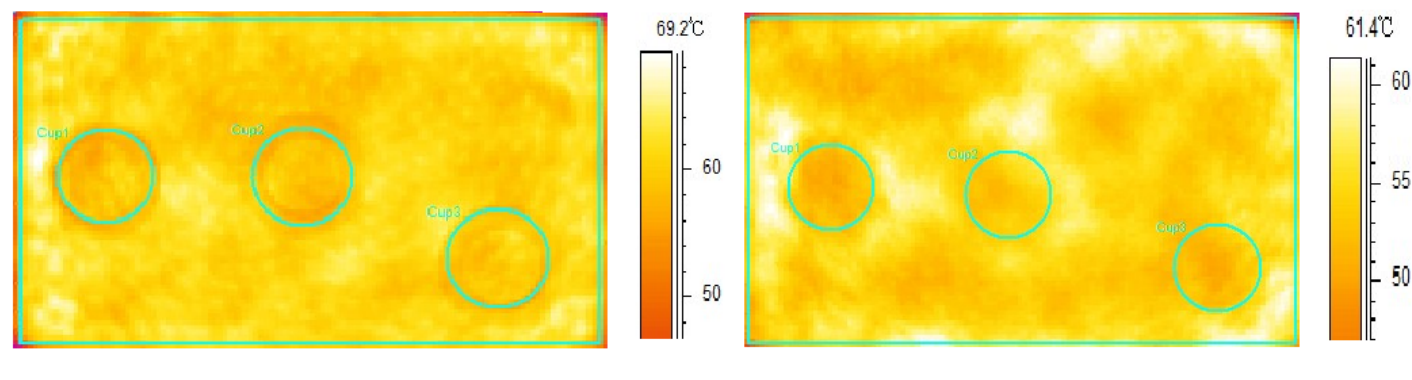

$\begin{array}{lllcrr}\text { Label } & \text { Min } & \text { Max } & \text { Max-Min } & \text { Avg } & \text { Stdev } \\ \text { Cup1 } & 55.0 & 62.5 & 7.4 & 58.6 & 1.6 \\ \text { Cup2 } & 55.4 & 63.0 & 7.6 & 58.6 & 1.3 \\ \text { Cup3 } & 55.0 & 63.8 & 8.8 & 59.5 & 1.3 \\ \text { Whole } & 46.2 & 69.5 & 23.3 & 61.0 & 2.0\end{array}$

(a)

$\begin{array}{lccccc}\text { Label } & \text { Min } & \text { Max } & \text { Max - Min } & \text { Avg } & \text { Stdev } \\ \text { Cup1 } & 49.9 & 57.9 & 8.0 & 52.4 & 1.3 \\ \text { Cup2 } & 51.7 & 57.1 & 5.4 & 53.8 & 1.2 \\ \text { Cup3 } & 50.1 & 56.5 & 6.4 & 52.6 & 1.2 \\ \text { Whole } & 47.0 & 61.7 & 14.7 & 54.9 & \mathbf{2 . 1}\end{array}$

(b)

Figure 10. Thermal images after RF heating under the electrode gap of $13.3 \mathrm{~cm}$ for the top surface of mixed beans when filled with (a) chickpea in the container and black-eyed pea at the reduced moisture content of $2.6 \%$ w.b. in the cups, and (b) lentil in the container and mung bean at the reduced moisture content of $3.7 \%$ w.b. in the three cups.

\section{CONCLUSION}

To validate proposed RF treatment protocols for cowpea weevil control in legumes, black-eyed pea and mung bean were selected as surrogate legumes with high laboratory infestation rates to mix with target legumes (chickpea and lentil) with low infestation rates. Density, specific heat, and dielectric properties of black-eyed pea and mung bean were measured and compared with those of chickpea and lentil. The results showed that the dielectric constant and loss factor of mung bean and black-eyed pea increased with increasing moisture content and temperature, which was in good agreement with the trends observed in lentil and chickpea. The final temperatures in black-eyed pea and mung bean were $6^{\circ} \mathrm{C}$ and $4^{\circ} \mathrm{C}$ higher than those in chickpea and lentil at the same RF treatment conditions when the temperature of the samples was raised to $60^{\circ} \mathrm{C}$ at initial moisture contents. The fast heating rate of mung bean and black-eyed pea in the RF unit might have been caused by the differences in both thermal and dielectric properties. By reducing the moisture contents in black-eyed pea and mung bean to $2.6 \%$ and $3.7 \%$, the heating rates during RF heating were lowered to below those of chickpea and lentil, suggesting that conservative validation results from subsequent insect mortality should be obtainable. Further research is needed to confirm the efficacy of infested insects and acceptable quality in RF-treated legumes.

\section{ACKNOWLEDGEMENTS}

This research was supported by grants from USDACSREES (2008-34103-19091), and Washington State University Agricultural Research Center. We thank Dr. Mark Casada for reviewing the manuscript and providing constructive suggestions.

\section{REFERENCES}

Ahmed, K., F. Khalique, M. Afzal, M. Tahir, and B. A. Malik. 1989. Variability in chickpea (Cicer arietinum L.) genotypes for resistance to Callosobruchus maculatus F. (Bruchidae). J. Stored Prod. Res. 25(2): 97-99.

Andreuccetti, D., M. Bini, A. Ignesti, A. Gambetta, and R. Olmi. 1994. Microwave destruction of woodworms. J. Microw. Power Electromagn. Energy 29(3): 153-160.
AOAC. 2002. Official Methods of Analysis. Gaithersburg, Md.: Association of Official Analytical Chemists.

Arbogast, R. T. 1991. Beetles: Coleoptera. In Ecology and Management of Food-Industry Pests, 131-176. J. R. Gorham, ed. Arlington, Va.: AOAC.

Barber, H. 1983. Chapter 8: Dielectric heating. In Electroheat. New York, N.Y.: Granada Publishing.

Ben-Lalli, A., J. M. Méot, A. Collignan, and P. Bohuon. 2011. Modelling heat-disinfestation of dried fruits on "biological model" larvae Ephestia kuehniella (Zeller). Food Research Intl. 44(1): 156-166.

Berbert, P. A., D. M. Queriroz, and E. C. Melo. 2002. Dielectric properties of common bean. Biosystems Eng. 83(4): 449-462.

Browner, C. M. 1999. 40 CFR Part 82: Protection of stratospheric ozone: Incorporation of Montreal Protocol adjustment for a 1999 interim reduction in Class I, group VI controlled substances. Federal Register 64(104): 29240-29245.

Carpenter, J., L. Gianessi, and L. Lynch. 2000. The economic impact of the scheduled U.S. phaseout of methyl bromide. Washington, D.C.: National Center for Food and Agricultural Policy.

Guo, W., G. Tiwari, J. Tang, and S. Wang. 2008. Frequency, moisture, and temperature dependent dielectric properties of chickpea flour. Biosystems Eng. 101(2): 217-224.

Guo, W., S. Wang, G. Tiwari, J. A. Johnson, and J. Tang. 2010. Temperature and moisture dependent dielectric properties of legume flours associated with dielectric heating. $L W T-$ Food Sci. Tech. 43(2): 193-201.

Islam, M. S., F. Akhter, R. Laz, and S. Parween. 2007. Oviposition preference of Callosobruchus maculatus (F.) to common pulses and potentiality of triflumuron as their protectant. J. Bio-Sci. 15: 83-88.

Jiao, S., J. A. Johnson, J. Tang, G. Tiwari, and S. Wang. 2011. Dielectric properties of cowpea weevil, black-eyed peas, and mung beans with respect to the development of radio frequency heat treatments. Biosystems Eng. 108(3): 280-291.

Lagunas-Solar, M. C., Z. Pan, N. X. Zeng, T. D. Truong, R. Khir, and K. S. P. Amaratunga. 2007. Application of radio frequency power for non-chemical disinfestation of rough rice with full retention of quality attributes. Applied Eng. in Agric. 23(5): 647-654.

Marra, F., L. Zhang, and J. G. Lyng. 2009. Radio frequency treatment of foods: Review of recent advances. J. Food Eng. 91(4): 497-508

Metaxas, A. C. 1996. Foundations of Electroheat: A Unified Approach. 1st ed. New York, N.Y.: John Wiley and Sons.

Mitcham, E. J., R. H. Veltman, X. Feng, E. de Castro, J. A. Johnson, T. L. Simpson, W. V. Biasi, S. Wang, and J. Tang. 2004. 
Application of radio frequency treatments to control insects in in-shell walnuts. Postharvest Biol. Tech. 33(1): 93-100.

Mudgett, R. E. 1994. Electrical properties of foods. In Engineering Properties of Foods, 389-455. M. A. Rao and S. S. H. Rizvi, eds. New York, N.Y.: Marcel Dekker.

Nelson, S. O. 1996. Review and assessment of radio-frequency and microwave energy for stored-grain insect control. Trans. ASAE 39(4): 1475-1484.

Nelson, S. O., and J. A. Payne. 1982. RF dielectric heating for pecan weevil control. Trans. ASAE 25(2): 456-458.

Piyasena, P., C. Dussault, T. Koutchma, H. S. Ramaswamy, and G. B. Awash. 2003. Radio frequency heating of foods: Principles, applications, and related properties: A review. Crit. Rev. Food Sci. Nutr. 43(6): 587-606.

Tang, J., S. Sokhansanj, S. Yannacopoulos, and S. O. Kasap. 1991. Specific heat of lentils by differential scanning calorimetry. Trans. ASAE 34(2): 517-522.

Tang, J., J. N. Ikediala, S. Wang, J. D. Hansen, and R. P. Cavalieri. 2000. High-temperature, short-time thermal quarantine methods. Postharvest Biol. Tech. 21(1): 129-145.

UNEP. 2006. Handbook for the Montreal Protocol on Substances that Deplete the Ozone Layer. 7th ed. Nairobi, Kenya: United Nations Environmental Program, UNEP Ozone Secretariat. Available at: http://ozone.unep.org/Publications/handbooks/ MP_Handbook_2006.pdf.

USADP LC. 2007. Policy position about trade barrier and restrictions. Moscow, Ida.: USA Dry Pea and Lentil Council.

Valdez-Fragoso, A., H. Mújica-Paz, J. Welti-Chanes, and J. J. Bimbenet. 2001. Effect of moisture and temperature on the specific heat of corn and rice determined by differential scanning calorimetry. In Intl. Congress on Engineering and Food, 14-17. J. Welti-Chanes, G. V. Barbosa-Cánovas, and J. M. Aguilera, eds. Lancaster, Pa.: Technomic Publishing.
Wang, S., J. N. Ikediala, J. Tang, J. Hansen, E. Mitcham, R. Mao, and B. Swanson. 2001. Radio frequency treatments to control codling moth in in-shell walnuts. Postharvest Biol. Tech. 22(1): 29-38.

Wang, S., J. Tang, J. A. Johnson, and J. D. Hansen. 2002. Thermal death kinetics of 5th-instar navel orangeworm (Lepidoptera: Pyralidae). J. Stored Prod. Res. 38(5): 427-440.

Wang, S., J. Tang, R. P. Cavalieri, and D. Davis. 2003a. Differential heating of insects in dried nuts and fruits associated with radio frequency and microwave treatments. Trans. ASAE 46(4): 1175-1182.

Wang, S., J. Tang, J. A. Johnson, E. J. Mitcham, J. D. Hansen, G. Hallman, S. R. Drake, and Y. Wang. 2003b. Dielectric properties of fruits and insect pests as related to radio frequency and microwave treatments. Biosystems Eng. 85(2): 201-212.

Wang, S., M. Monzon, J. A. Johnson, E. J. Mitcham, and J. Tang. 2007a. Industrial-scale radio frequency treatments for insect control in walnuts: I. Heating uniformity and energy efficiency. Postharvest Biol. Tech. 45(2): 240-246.

Wang, S., M. Monzon, J. A. Johnson, E. J. Mitcham, and J. Tang. $2007 \mathrm{~b}$. Industrial-scale radio frequency treatments for insect control in walnuts: II. Insect mortality and product quality. Postharvest Biol. Tech. 45(2): 247-253.

Wang, S., G. Tiwari, S. Jiao, J. A. Johnson, and J. Tang. 2010. Developing postharvest disinfestations treatments for legumes using radio frequency energy. Biosystems Eng. 105(3): 341-349. 